
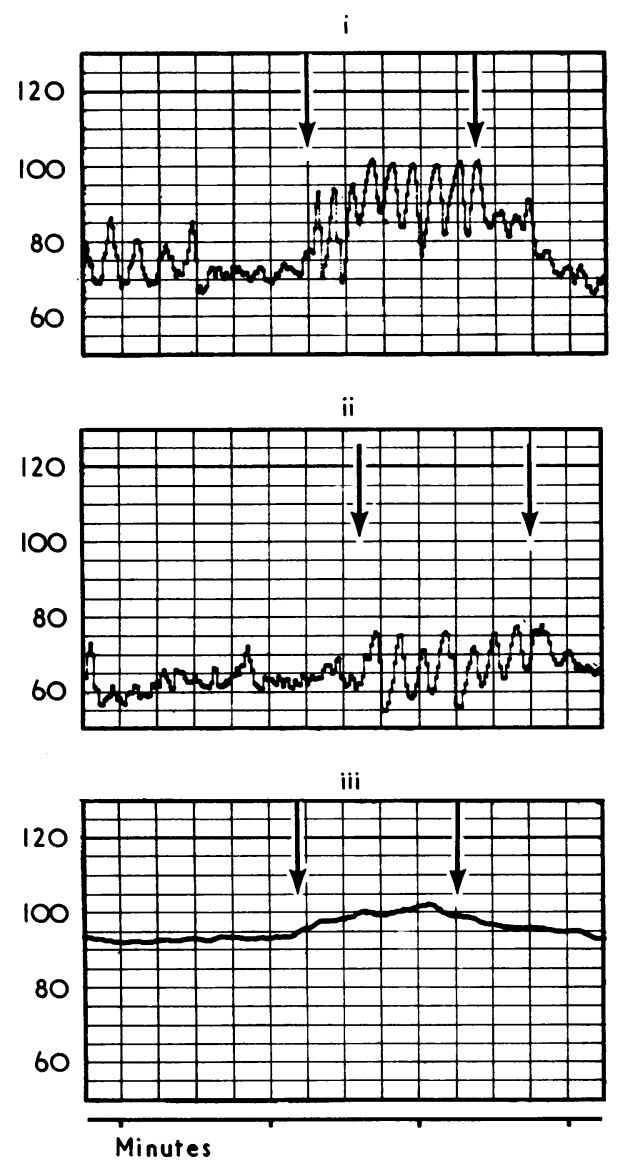

FIG. 6-Effect of intravenous propranolol and atropine on beat-to-beat variation in healthy man aged 30 years (i) before drug administration, (ii) after $10 \mathrm{mg}$ propranolol, (iii) after 1.8 mg atropine. Arrows mark points between which deep breaths were taken.

The dominance of vagal control over beat-to-beat variation (Levy and Zieske, 1969) is indicated by the raised heart rate of the pharmacologically denervated heart (Turner, 1969) and of the transplanted heart, which is, of course, denervated (Griepp et al., 1971). Moreover, sympathetic inhibition by the administration of propranolol to normal subjects has no effect on beat-tobeat variation (fig. 6). These observations lend further support to the theory that loss of vagal tone is responsible for the absence of beat-to-beat variation in diabetics with autonomic neuropathy.

Measurement of cardiac beat-to-beat variation provides objective evidence for the presence of autonomic neuropathy. The test is simple and reproducible and serial observations can easily be made. Certain clinical observations such as the persistent sinus tachycardia found in some patients may be accounted for by vagal denervation of the heart. Two patients (cases 1 and 3) each had two "unexplained" cardiac arrests, and one might speculate that these episodes were in some way the consequence of cardiac denervation.

We should like to thank Professor S. G. Clayton and Dr. D. A Pyke for their encouragment and advice, Dr. Roger Lloyd-Mostyn for ferforming some of the autonomic function tests, and Dr. Trever Shelley (Guy's Hospital) for technical help. T. W. was suppcried by a grant from the Wates Foundation.

Feques ${ }^{\star}$ for reprints should be sent to Dr. P. J. Watkins

\section{References}

Angelone, A., and Coulter, N. A. (1964). Journal of Applied Physiology, 19, 479.

Chamberlain, D. A., Turner, P., and Sneddon, J. M. (1967). Lancet, 2, 12. Clynes, M. (1960). Science, 131, 300.

Friedberg, C. K. (1966). In Diseases of the Heart, p. 486. Philadelphia, Saunders.

Griepp, R. B., Stinson, E. B., Dong, E., Clark, D. A., and Shumway, N. E. (1971). Surgery, 70, 88.

Keen, H. (1959). Postgraduate Medical fournal, 35, 272

Levy, M. N., and Zieske, H. (1969). Fournal of Applied Physiology, 27, 465. Levy, M. N., and Zieske, H. (1969). Journal of Applied Physiolo

Samaan, A. (1935). Journal of Physiology, 83, 332 .

Samaan, A. (1935). Journal of Physiology, 83, 332.

Sayers, B. M. (197). Proceedings of the Royal Society of Medicin

Sharpey-Schafer, E. P., and Taylor, P. J. (1960). Lancet, 1, 559. Turner, P. (1969). In Clinical Aspects of Autonomic Pharmacology, p. 84. London, Heinemann

Vallbona, C., Cardus, D., Spencer, W. A., and Hoff, H. E. (1965). American fournal of Cardiology, 16, 379

Watkins, P. J. (1973). British Medical fournal, 1, 583.

\title{
From Phisohex to Hibiscrub
}

\section{H. G SMYLIE, J. R. C. LOGIE, G. SMITH}

\section{Summary}

In a field trial of three disinfectant-detergent preparations for the surgical scrub Hibiscrub (a $4 \%$ chlorhexidine detergent solution) maintained a significantly greater residual antibacterial action on the skin of the gloved hands of an operating team than was obtained with Disadine (povidone-iodine detergent preparation) $(P<0.001)$. In comparison with Phisohex $(3 \%$ hexachlorophane in detergent cream), the established surgical scrub of the operating team for many years, Hibiscrub

\section{University of Aberdeen, Aberdeen AB9 2ZD}

H. G. SMYLIE, M.D., M.R.C.PATH., Senior Lecturer in Bacteriology J. R. C. LOGIE, M.B., CH.B., Research Fellow in Surgery G. SMITH, CH.M., P.R.C.s., Regius Professor of Surgery maitained marginally more significant residual disinfection (P 0.05). Of the three preparations the members of the team found Hibiscrub to be more acceptable for use than either Disadine or Phisohex.

\section{Introduction}

Since the first British report on Phisohex (Smylie et al., 1959), $3 \%$ hexachlorophane detergent preparations have dominated the choice of safe and effective agents for the surgical scrub regimen. There is no doubt that both in this field (Lowbury et al., 1960, 1963) and in others, notably infant care (Plueckhahn and Banks, 1963; Baber et al., 1967), the disinfectant hexachlorophane has been shown to contribute significantly to the control of hospital cross-infection. As a narrow spectrum agent acting mainly against skin cocci the continuous use of this compound has been criticized (Forfar et al., 1968) because it gives a selective encouragement to Gram-negative infections. This, together with recent reports on the possibility of its toxic absorption 
(Curley et al., 1971; Kimbrough, 1971), has emphasized the need for an efficient and acceptable alternative.

Such a preparation would require to be non-toxic, hypoallergenic, cumulatively microbicidal, effectively detergent, nonirritant, and pleasant to handle-a tall order which over the past decade has disqualified numerous competitors in this field. The marketing of a new product Hibiscrub (a $4 \%$ chlorhexidine detergent preparation) by I.C.I., Ltd. laying claim to the above properties stimulated the professorial surgical unit in Aberdeen Royal Infirmary to carry out a field trial of Hibiscrub and one other currently popular product, the povidone-iodine detergent preparation Disadine, as possible alternatives to Phisohex.

\section{Conduct of Field Trial}

\section{OPERATING TEAM}

This was taken to mean surgeon, nurse, and assistants. As these roles were filled from a unit staffing pool the composition of the team could change between operations, but lists were generally completed by the same team. Phisohex has been used exclusively for many years by this unit.

\section{METHOD OF ASSESSMENT}

In this type of field trial elaborate methods of sampling are generally unsuccessful, either ruining collaboration by inducing impatience in clinical staff or because they are physically traumatic. Thus skin biopsy, self-adhesive tape stripping, and the cylinder-scrub technique (Selwyn and Ellis, 1972) were not considered. Price's (1938) technique and all its subsequent modifications is suitable only for laboratory experiments. The recently evolved glove fluid procedure (Peterson, 1972) which measures near total numbers of removable organisms from the gloved hand is cumbersome and has yet to be proved free from experimental error. For these reasons the original plate-streak technique used by this unit in their earlier work with Phisohex was retained. The finger and thumb pads of both hands of each member of the team were streaked in a regular pattern across agar plates incorporating disinfectant inhibitors $(1 \%$ Tween 80 , $0.5 \%$ lecithin, and $1 \%$ sodium thiosulphate) immediately gloves were removed after operation. Samples showing no growth were tested with sensitive cultures to assess carry-over of disinfectant. All plates were incubated aerobically for 24 hours at $37^{\circ} \mathrm{C}$ and stored on the bench for a further 48 hours before colony identification and counting. Records were kept of each operative procedure and the progress of all wounds was followed up to show any change in the incidence of postoperative sepsis.

The trial contained four consecutive periods of study. Period 1-Base-line measurement of the efficiency of the current hexachlorophane detergent (Phisohex) regimen (154 operations studied). Period 2-Change to chlorhexidine detergent (Hibiscrub) (228 operations studied). Period 3-Return to Phisohex and re-establishment of baseline measurement (262 operations studied). Period 4-Change to povidone-iodine detergent (Disadine) (222 operations studied).

At the end of period 4 each member of the team completed a questionnaire which required an opinion on lathering power, after-use skin dryness, irritation, colour, scent, and, assuming all three agents to have equal microbicidal properties, their overall preference.

\section{Results}

\section{BACTERIOLOGY}

\section{Plate-streak Sampling}

The results of the trial are shown in the table. In each period all counts obtained from individual finger-streaks from both hands were totalled, combined, and averaged against the number of operations involved. This average mean postoperative colony count could then be used to show the state of the hands for each role in the operating team during each period of disinfection and as a comparison of one disinfection period with another. Because many operations were performed with one rather than two assistant surgeons this group has been treated as a single individual.

All cultures from individual members of the operating team yielding fewer than five colonies per operation were classed as negative, five and more as positive. A $\chi^{2}$ analysis of negative versus positive counts was then applied to each individual team role. This showed that periods 1,2 , and 3 (Phisohex and Hibiscrub usage) for each role did not differ significantly $(P>0 \cdot 1)$, that the two Phisohex treatment periods did not differ $(P>0 \cdot 1)$, but that on combining these two baseline measurement periods for comparison with period 2 Hibiscrub appeared to be a better treatment than Phisohex though the difference was of borderline significance (P 0.05). The major difference was for period 4 which gave counts above 5 significantly more often $(P<0.001)$ than did the other periods.

It is apparent that average mean postoperative counts are proportional to the manual activity of the individual. The diagram illustrating this (fig. 1) also shows the dominant hand count for surgeon and nurse to be right and left respectively. The thumb and index finger pads were the most heavily contaminated in all three roles.

The comparative inefficiency of hexachlorophane incorporated in bar soap rather than in Phisohex has been well documented (Lowbury and Lilly, 1960), and it emerged again during this trial. The team was joined latterly by an operator preferring Deryl soap (hexachlorophane $2 \%$ incorporated in ordinary bar soap) to Phisohex. From 48 scrubs with Deryl he produced an average postoperative colony count of $100 \cdot 5$. This compared so unfavourably with his average count of 4 from the 24 scrubs contributed to period 2 (Hibiscrub) that he voluntarily followed the format of the remainder of the field trial. Subsequently 24

Cultural Result from Each Trial Period showing Average Mean Postoperative Colony Counts for Individual Team Roles and Negative versus Range of Positive Plate-streak Counts. All counts above 500 were given the value 500

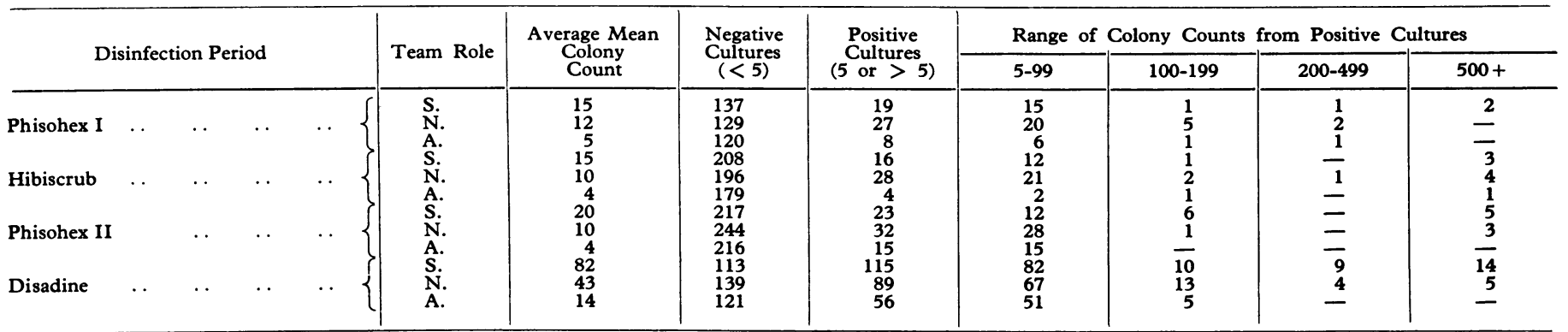




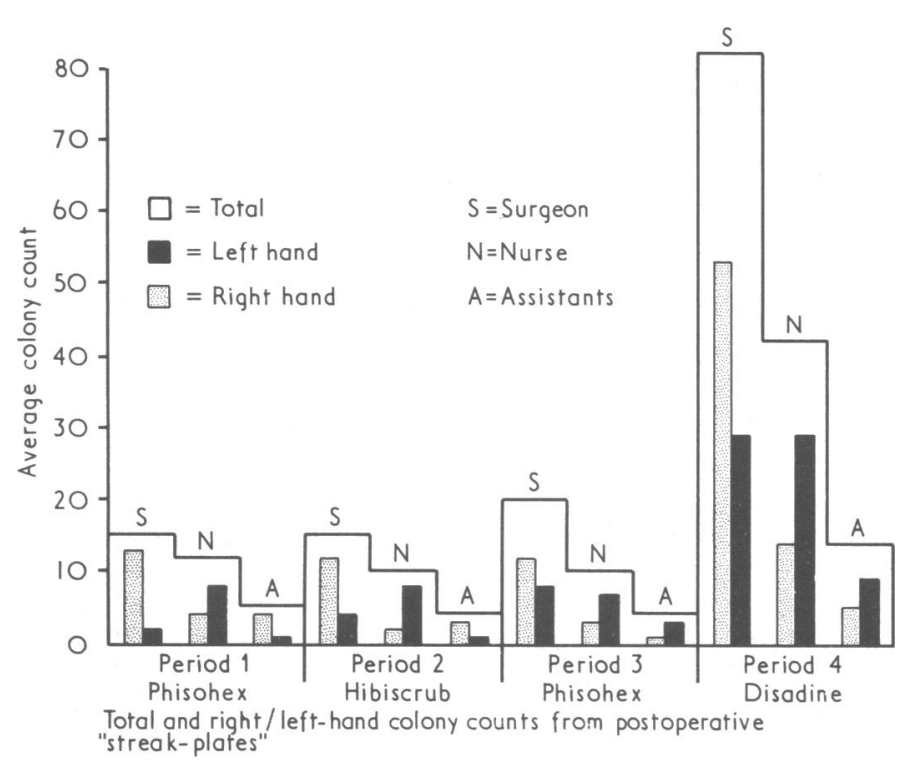

FIG. 1-Total and right/left-hand colony counts from postoperative "streak plates." (To ease illustration of such a large amount of data, counts have been drawn to represent levels and not comparative areas, and should be read accordingly.

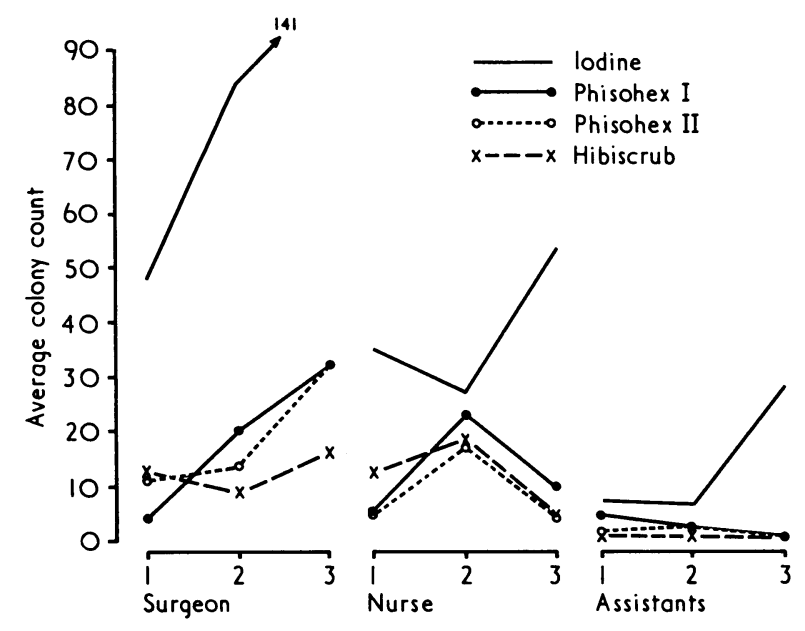

FIG. 2--Average mean postoperative colony counts for different team roles after one-, two-, and three-hour operative procedures.

scrubs in period 4 (Disadine) by this operator yielded an average count of $129 \cdot 7$.

The pattern of residual disinfectant action during the wearing of rubber gloves was detected by separating operations into one-, two-, and three-hour procedures. A comparison of average mean postoperative colony counts for each role in the team at the end of each type of procedure is shown in fig. 2. At the end of one-hour procedures counts from period 4 of the trial (Disadine) were already three to four times higher for the surgeon and nurse compared with those obtained from the first three trial periods (Phisohex and Hibiscrub). This difference increases for the surgeon engaged in two-hour procedures, but not for nurses or assistants. By the end of three-hour procedures all members of the team using Disadine yielded counts ranging from four to nine times larger than those obtained with either Hibiscrub or Phisohex.

The low counts obtained during Hibiscrub usage were not significantly increased in relation to either length of operative procedure or team role. Counts obtained during Phisohex usage followed a similar order and pattern except for the surgeon who appears to have increased his count according to length of operative procedure.

Staphylococcus epidermidis was the dominant growth. Staph. pyogenes was identified on three occasions, twice during period 1 and once during period 4 . There were never more than two colonies in a mixed growth.

Follow-up of all patients showed no significant difference in the incidence of postoperative wound sepsis or of crossinfection. The systematic study of the incidence of postoperative wound infection has been continuous in this unit since 1964.

\section{ACCEPTABILITY OF PRODUCT}

This was assessed from the questionnaire answers given by the 23 members of the team. A clear preference for Hibiscrub emerged. Undesirable side effects occurred mostly with Disadine (18 subjects), then Phisohex (11), and Hibiscrub (4).

\section{Discussion}

In this field trial the professorial surgical unit in collaboration with the department of bacteriology of the University of Aberdeen provided material from 870 operative procedures to permit comparison of two previously unused disinfectantdetergent preparations with an already well-established surgical-scrub regimen. The direct contact method of sampling chosen to suit the exigencies of this type of field trial is free from many of the experimental errors which beset indirect sampling methods.

A gratuitous experimental control was provided by the operator who joined the team latterly using Deryl soap in preference to Phisohex. The resultant postoperative colony counts fall directly in line with the observations of Lowbury and Lilly (1960) which showed the size of the discrepancy in the antibacterial action of hexachlorophane in bar soap as opposed to Phisohex. We think this is confirmatory evidence that the plate-streak technique is an adequately sensitive indicator of disinfectant action in this type of field trial.

Prewash and initial postwash sampling, omitted from this trial, has already been accurately assessed for all three disinfectant principles (Lilly and Lowbury, 1971; Michaud, et al. 1972; Peterson, 1972; Lowbury and Lilly, 1973). The latter show a significantly greater mean immediate reduction of prewash bacterial counts after one application of Hibiscrub $(86.7 \%)$ in comparison with either Disadine $(68.0 \%)$ or the hexachlorophane detergent cream Disfex (61-34\%). Their observations show that after six successive hand washes spread over two days there was little difference between the three preparations in the eventual reduction of skin flora, both Disadine and Disfex having virtually caught up with the Hibiscrub effect. Measurements, however, were made from the ungloved hand. Some indication of an entirely different cumulative result from gloved hands is given in Peterson's (1972) report on the glove-fluid procedure. In this study the immediate initial reductions of prewash counts for Phisohex in comparison with Betadine (povidone-iodine detergent) match those of Lowbury and Lilly. However, after rubber gloves had been worn for two hours Betadine-treated hands regularly yielded counts more than double the initial count while as expected a further $80 \%$ redustion of initial Phisohex counts took place. In the Aberdeen field trial, with Phisohex to establish a baseline against which the other two products were measured, it was seen that the average mean postoperative colony counts obtained during period 4 were significantly higher (about four times) than in any of the other three periods. This indicates failure of povidone-iodine detergent to maintain an adequate residual or cumulative disinfectant action on the working gloved hand. This is apparent during one- and two-hour procedures, is most 
pronounced over three-hour procedures, and appears proportional to the degree of manual activity within the team.

There is no doubt that palmar sweat contains a variety of substances capable of inactivating iodine. Unless the Disadine scrub is followed by a continuous release of available iodine throughout the operative procedure, failure to deal with recolonizing skin bacteria may be expected. This hypothesis is the subject of further studies.

The dominance of right and left hand contamination of surgeon and scrub-nurse respectively remains an unexplained observation. It was not due to a majority of left-handed nurses. In an earlier study in this unit Davidson (1969) showed glove puncture to occur most commonly on the left hand of the surgeon and the right hand of the scrub-nurse. This was thought to be due to the different way in which they handled suture needles. In the current trial the glove puncture rate remained constant throughout.

\section{Conclusion}

It is felt that the bacteriological result of this field trial adds significantly to the information required in an approach to an ideal surgical scrub technique. It is clear that on gloved hands Disadine failed to achieve the residual or cumulative antibacterial action shown by both Phisohex and Hibiscrub. Correlative interpretation of our own results with those of other workers suggest that of the small list of products available for the preparation of the hands of operating teams the new $4 \%$ chlorhexidine detergent performs as well if not better than
Phisohex during even the longest operative procedure. It has, moreover, a broader antibacterial spectrum, and produces a greater initial reduction of the bacterial contamination of the skin of the hands. It was found to be more acceptable in use and cheaper than either Disadine or Phisohex. These factors combined to convince the members of the trial team that Hibiscrub should now displace Phisohex in their surgical scrub regimen.

Gra:eful thanks are due to Dr. G. Hems for the statistical evaluat on, to Professor A. Macdonald for his helpful crit:cism of the parer, and to the theaire and medical staff for their co-operation.

\section{References}

Baber, K. G., et al. (1967). Fournal of Hygiene, 651, 381.

Curley, A., Hawk, R. E., Kimbrough, R. D., Nathenson, G., and Finberg, L. (1971). Lancet, 2, 296.

Davidson, A. I. G. (1969). Ph.D. Thesis, Aberdeen University.

Forfar, J. O., Gould, J. C., and MacCabe, A. F. (1968). Lancet, 2, 177.

Kimbrough, R. D. (1971). Archives of Environmental Health, 23, 119.

Lilly, H. A., and Lowbury, E. J. L. (1971). British Medical fournal, 3, 674.

Lowbury, E. J. L., and Lilly, H. A. (1960). British Medical fournal, 1, 1445.

Lowbury, E. J. L., Lilly, H. A., and Bull, J. P. (1960). British Medical fournal, 2,1039 .

Lowbury, E. J. L., Lilly, H. A., and Bull, J. P. (1963). British Medical Fournal, 1, 1251 .

Lowbury, E. J. L., and Lilly, H. A. (1973). British Medical fournal, 1, 510.

Michaud, R. N., McGrath, M. B., and Goss, W. A. (1972). Antimicrobial Agents and Chemotherapy, $2,8$.

Peterson, A. F. (1972). Development in Industrial Microbiology, vol. 14. In press.

Plueckhahn, V. D., and Banks, J. (1963). Lancet, 2, 519.

Price, P. B. (1938). Fournal of Infectious Diseases, 63, 301.

Selwyn, S., and Ellis, H. (1972). British Medical fournal, 1, 136.

Smylie, H. G., Webster, C. U., and Bruce, M. L. (1959). British Medical fournal 2, 606,

\title{
New Type of Allergic Asthma due to IgG "Reaginic" Antibody
}

\author{
D. H. BRYANT, M. W. BURNS, L. LAZARUS
}

\section{Introduction}

Though it is generally accepted that the antibodies responsible for immediate allergic reactions in man belong to one immunoglobulin class-IgE (Ishizaka and Ishizaka, 1967)-there is circumstantial evidence that other antibodies may be acting as reagins in some asthmatic patients.

It has been shown that circulating IgE levels may be normal in some allergic asthmatic subjects (Bennich and Johansson, 1971), and specific IgE antibodies have not been found in $25 \%$ of those who have a positive bronchial response to specific allergens (Aas and Johansson, 1971; Stenius et al., 1971). Furthermore, though disodium cromoglycate (DSCG) is an effective inhibitor of IgE-mediated allergic reactions (Cox, 1971), in several clinical trials it has been shown that it is effective in treating only $70 \%$ of patients with allergic asthma (Munro-Ford, 1971; Silverman et al., 1972). In addition disodium cromoglycate does not always suppress immediate allergic reactions elicited by bronchial provocation tests (Muittari, 1971).

Immediate allergic reactions in experimental animals are mediated by two types of antibody (Bloch and Ohman, 1971), one of these having the features of human $\operatorname{IgE}$, the other being an IgG antibody. There is one report of "short-term anaphylactic IgG antibodies" occurring in man, and that was in a group of patients with food allergy (Parish, 1970).

The present study was undertaken to determine whether a group of asthmatic patients with immediate allergic bronchial 